\title{
Review of Mackenzie, J. Lachlan and Laura Alba-Juez (eds.). 2019. Emotion in Discourse. Amsterdam and Philadelphia: John Benjamins
}

\author{
Marianna Ryshina-Pankova \\ Georgetown University \\ Washington, DC, USA
}

For citation:

Ryshina-Pankova, Marianna. 2020. Review of Mackenzie, J. Lachlan and Laura Alba-Juez (eds.). 2019. Emotion in Discourse. Amsterdam and Philadelphia: John Benjamins. Russian Journal of Linguistics 24 (2). 506-514. DOI: 10.22363/2687-0088-2020-24-2-506-514

Рецензия

\section{Рецензия на книгу \\ Mackenzie, J. Lachlan and Laura Alba-Juez (eds.). 2019. Emotion in Discourse. Amsterdam and Philadelphia: John Benjamins}

\author{
Марианна Рышина-Панкова \\ Джорджтаунский университет \\ Вашингтон, округ Колумбия, США
}

\section{Для цитирования:}

Ryshina-Pankova, Marianna. 2020. Review of Mackenzie, J. Lachlan and Laura Alba-Juez (eds.). 2019. Emotion in Discourse. Amsterdam and Philadelphia: John Benjamins. Russian Journal of Linguistics 24 (2). 506 - 514. DOI: 10.22363/2687-0088-2020-24-2-506-514

Emotion in Discourse, a collection of articles edited by two prominent linguists J. Lachlan Mackenzie from Vrije Universiteit Amsterdam and Laura Alba-Juez from Universidad Nacional de Educación a Distancia (UNED), Madrid, instantiates what has been called the "emotional turn" in the human sciences and specifically in the study of language (see also Alba-Juez \& Larina, 2018, a special issue of this journal devoted to this theme). The volume focuses on the crucial importance of emotion in human communication and on the construal of emotions through language. Presenting the latest theoretical and empirical research on this matter, the 
book aims to provide a detailed account of the interaction of emotion, language, language proficiency, culture, and discourse.

The first chapter, by Laura Alba-Juez and Lachlan Mackenzie, gives an overview of the different approaches to emotion in linguistics and psychology and lists the main research questions underlying the book. These concern the issue of differentiating between evaluative and emotive discourse, the contribution of research in psychology to our understanding of the language of emotions, and the relationship between pragmatic competence, expression of emotion, and emotional intelligence among others. The editors provide their own definition of emotion that serves as the guiding conceptualization for the entire book: "...we view emotion as a (dynamical) system of language which interacts with the system of evaluation but whose main function is the expression of the speaker's feelings, mood or affective experience. It is a multimodal discourse process, which permeates all linguistic levels but also manifests itself in non-verbal ways, presenting different stages and forms (influenced by variables such as pragmatic expectations or common-ground knowledge) according as the discursive situation and interaction changes and evolves." (p. 18). The chapter ends with a short summary of each of the 13 studies in the volume that are grouped under four large themes: Expression of emotion at the different linguistic levels, pragmatics and emotion, interdisciplinary approaches to emotion, and emotions in different discourse types.

The first section, which includes five studies on the construal of emotions through specific lexicogrammatical resources, opens with a chapter by Monika Bednarek (Chapter 2) whose focus is on the multiple functions of swear or taboo words. Some foundational knowledge of the systemic functional (SFL) theory of language is presupposed, as Bednarek problematizes the theoretical conceptualization and terminology used to describe swear/taboo words in this framework and presents a new theorization of these evaluative resources in SFL discourse semantics. The new model assigns three main functions to these wordsexpression of emotion, emphasis/intensification, social distance/solidarity, and a stylistic/idiomatic function - and places them within specific discourse semantic systems in the SFL model, such as Appraisal and its subsystems of Affect, Graduation, and Engagement. In the empirical part of the chapter that reports on a corpus-based analysis of the Sydney Corpus of Television Dialogue, the author illustrates how some of these functions of swear words work for the purposes of the specific genre in question, such as creating realism, constructing setting and happenings, the characterization of protagonists, and exploitation of the resources of language for creating humor. In conclusion, Bednarek points out the usefulness of corpus-based studies for identifying patterns of usage and functions.

In Chapter 3, Lachlan Mackenzie continues the topic of swear words but takes a different perspective on them. Drawing on the theoretical framework of Functional Discourse Grammar (FDG) (Hengeveld \& Mackenzie, 2008), the researcher examines different uses of the taboo word "fuck" and its derivatives. The following types of uses are identified: literal representation use, single discourse 
act, metaphorical representation, lexical substitution, and expletive use, which is the focus of the chapter. While the study does not provide much information on the contexts of use and is not based on an analysis of a corpus, it does present insightful examples of uses of this swear word and delineates the peculiarities of its syntactic distribution in the expletive function. The author concludes that while the expletive use of these constructions reveals high emotional involvement, their grammatical and syntactic properties are not innovative and can be captured by reference to the existing grammatical model of FDG.

In Chapter 4, Angela Downing and Elena Martinez Caro point out the significance of another linguistic structure for the study of emotions in discourse, that of interjections. In particular, in their corpus-based study, the authors investigate the origins of the expression "gosh," the frequency of its use, differences in American and British English usage, and its syntactic behavior: positioning, surrounding elements and co-occurrence with mood type. The authors identify the following evaluative functions of this interjection: expression of emotion, intensification, the speaker's state of knowledge, and a discourse-structuring function.

In Chapter 5, rather than focusing on specific linguistic forms, as in the previous chapters, Ruth Breeze and Manuel Casado-Velarde turn to a crosslinguistic investigation of the phraseology of emotions that compares expression of feelings in English and Spanish with a particular focus on metaphoric language and specifically on metaphorical expressions with no explicit reference to feelings as such (as in "bite the bullet"). Taking a 'philological approach,' the researchers first identify these expressions from English and Spanish dictionaries of idioms and then analyze those that indicate the absence and presence of emotions and those that refer to the vague emotions, the impact of powerful emotions, and the ability to experience and control strong emotions. Drawing on the work of cognitive linguistics (Kövecses, 2000; Lakoff \& Johnson, 1980), the authors discuss and illustrate various recurring schemata (for example, emotion as a captive animal; emotion associated with a rise in temperature) used for expressing emotions in the two languages and pose as a question for future research whether these common schemata reflect universal embodied experiences or a common cultural heritage. One of the interesting findings is the attribution of differences in conventional English and Spanish metaphorical construals of emotions to a cultural filter, for example, the locus of emotions in Spanish as "innards" or the positive meaning of "cool" in reference to emotions in English (as in "keep one's cool"). The authors conclude their chapter by calling for the construction of an onomasiological dictionary of emotions that would catalogue various language-specific expressions of emotion, thus recording shared cultural experiences and memories and helping L2 language users learn about them.

Ad Foolen, in Chapter 6, draws attention to the value of specific lexical items - "left" and "right" - that we do not immediately interpret as evaluative. Starting with an elegant and pertinent epigraph, the author explores the positive and 
negative valence of these words diachronically and across different cultures. $\mathrm{He}$ explains the valence with reference to the bodily dimension of handedness: right hand as a stronger hand, right-handedness as a typical trait for the majority of humans, and the lateralization of emotion. Furthermore, the chapter explores the valence of "left" and "right" in various domains of culture: in art, in religion, and in two types of discourse, those of politics and traffic. In conclusion, the author emphasizes cross-cultural differences in the salience of the valence and in its polarity and suggests examination of the positive and negative connotations of "left" and "right" in different types of discourses as a future area of research.

The next section of the book, "Pragmatics and emotion", stresses the importance of feelings in everyday communication and examines the expression of emotions in various interactional contexts. In Chapter 7, Francisco Yus explores the characteristics of Internet-based communication from the perspective of cognitive pragmatics. In particular, he describes the phatic (i.e., oriented towards establishing social ties rather than rendering propositional content) nature of interaction in text messaging and on social networks. The chapter gives an insightful account of the positive contextual affordances of the mobile phone, as well as of positive nonpropositional phatic effects of instant messaging and other online interactions that explain the common addiction to the screen. Interestingly, the author points to scenarios where the phatic aspects of interaction are beyond the intentions of the sender and are not necessarily consciously noted by the addressees, yet form a residue that gives value to the mundane propositional content.

Chapter 8 continues the focus on what can be considered another example of phatic interaction, namely on humorous banter that elicits the emotion of mirth. Salvatore Attardo is interested in how humor interactions that last for more than 3 turns are marked and sustained. Counter to expectation, Attardo provides research evidence that shows that it is not pauses, difference in the pitch or volume or even laughter that key conversations as humorous, but predominantly the facial expression of smiling and the "smiling voice" phenomenon. The author further elaborates that the presence of humor co-occurs with increased smiling intensity, various stages of which are carefully defined, which, through the activation of mirror neurons, prompts the interlocutor to produce the same facial gesture and continue the humorous exchange, contributing to "the virtuous circle of humor."

Chapter 9 by Nina-Maria Fronhofer concludes the section by addressing the complexity of emotion discourse through a conceptual model of Emotion Events that incorporates but also extends the systemic functional Appraisal framework (Martin \& White, 2005). This model aims to capture both emotion talk and emotional talk (Bednarek, 2008). Fronhofer's study is based on the contrastive corpus-based investigation of epistemic markers in experimentally elicited narratives written by British and German university students in response to 2 types of prompts, one about receiving an unfair mark and the second one about getting the highest mark. Epistemic markers were coded in the immediate linguistic context of emotion lexemes, specifically those that express anger. Presenting the results of 
the quantitative and qualitative analysis, the author convincingly demonstrates the important function epistemic markers play as resources for boosting or attenuating emotions on the one hand and for presenting them in dialogically contracting or expanding ways, on the other. The chapter also reveals interesting findings with regard to gender and cross-cultural differences in the use of these resources across English and German.

Section 3, on interdisciplinary approaches to emotion, opens with a study by Alba-Juez and Juan-Carlos Pérez-González (Chapter 10) that aims to investigate the relationship between aspects of emotional intelligence (EI) and pragmalinguistic competences (PC). Drawing on the theory of emotional competence (Mikolajczak, 2009) and communicative competence as used in the Common European Framework of Reference for Languages (Council of Europe, 2001), the authors designed a study that uses written responses by the employees, L1 users of Spanish, of five engineering companies to an emotionally laden scenario related to work, an elicitation test of emotive vocabulary for assessing PC, and a psychometric questionnaire for measuring an aspect of EI. Politeness Theory (Brown \& Levinson, 1987), Appraisal Theory (Martin \& White, 2005), and eimplicature (Schwarz-Friesel, 2010) are employed as methodological tools for the analysis of pragmalinguistic competence and the characteristics of Trait Emotional Intelligence (TEI) that includes perception of emotions, expression of emotions and empathy as a critical construct for the analysis of EI. Creative study design and a thorough analysis backed up by strong interrater reliability measures resulted in insightful findings. The most interesting of them is a positive association between a medium level of TEI and better results in PC. More studies with larger sample sizes would be needed to corroborate the result and explore its implications.

A further illustration of applying an interdisciplinary lens to the study of emotions, Chapter 11 by Jean-Marc Dewaele, Pernelle Lorette and Konstantinos V. Petrides aims to investigate the impact of cultural, linguistic and psychological profiles of individuals on their ability to recognize emotions (ERA). Utilizing an ecologically valid methodological approach that included audio-visual recordings of scenarios related to basic emotions (i.e., happiness, sadness, anger, fear, surprise, and disgust) performed by a British actress, the researchers asked British and American users of English as an L1 to identify the portrayed emotions in order to measure their ERA score. This score was juxtaposed with the results on a lexical test that has been considered to be a good indication of language proficiency in general and the scores on the Trait Emotional Intelligence (Trait EI) Questionnaire. The results reveal various interesting interactions between the variables. With regard to cultural influences, the results did not support the original research hypothesis about an in-group advantage in ERA for British L1 users, perhaps due to the relative similarity in cultures. Most interestingly, the hypothesis about the effect of linguistic proficiency on the ERA score was confirmed, which means that a higher proficiency helped in identifying emotions. And finally, with regard to the psychological characteristics, participants with a higher score on the Trait EI survey 
were also better at recognizing emotions. The authors also found a relationship between higher linguistic proficiency and Trait EI. They suggest exploring this relationship in future research, as they hypothesize that individuals who exhibit such characteristics of Trait EI as, for example, adaptability, emotion expression and management may be able to reach superior levels of linguistic proficiency in their L1. At the same time, one of the most unexpected aspects of the interaction between linguistic proficiency and Trait EI was that individuals with lower linguistic proficiency were able to recognize emotions better if their level of Trait EI was high.

Chapter 12 by Miguel-Ángel Benítez-Castro and Encarnación HidalgoTenorio is one of the most fascinating in the volume as it presents an interdisciplinary, linguistic and psychological approach to the enhancement of Appraisal Theory (Martin \& White, 2005) as one of the most powerful frameworks to date for describing the linguistic encoding of evaluation and specifically emotions. Taking Bednarek's work (2008) on revising the subsystem of Appraisal Theory, Affect, one step further, the authors use psychological emotion theories and data from the British National Corpus to refine the SFL-based taxonomy of emotions by addressing inconsistencies, reconciling theoretical gaps, and clarifying the fuzziness of different categories. A thorough presentation of linguistic, psychological and neuroscientific evidence allows the authors to convincingly argue for reorganizing the Appraisal system, rethinking some categories, and redrawing the boundaries between others. They propose to revise the taxonomy of Affect by foregrounding the role of goals, needs, and motivations as forming the basis of all emotional experience rather than as a factor for only one category of Affect--dis/satisfaction, as in the current Appraisal model. In line with this principle, the authors suggest differentiating between goal-seeking emotions, goalachievement emotions, and goal-relation emotions, with each category further divided into specific types of feelings. While some questions arise about the terminology or fit of some evaluative lexis within a particular category, overall this new model seems to offer a more differentiated and psychologically grounded view on the encoding of emotions in discourse and should inspire further (qualitative and corpus-based) studies that would put it to the test.

The last section of the book includes two qualitatively oriented studies that reveal the role of emotions in journalistic and scientific discourses. Chapter 13 by Isabel Alonso Belmonte uses the SFL approach, Transitivity and Appraisal, specifically the subsystem of Attitude (Affect, Judgment, Appreciation), to analyze emotional meaning in newsbites on the controversial eviction crisis in Spain published online in the Spanish newspaper El Pais in 2014. The author is interested in identifying the types of participants construed by the newsbites and distinguishes the three most salient roles that appear in this genre: "victims" referring to evicted, "heroes" referring to anti-eviction activists, and "villains" referring to police, banks or the national government who forced eviction. While such interpretation of the discourse participant roles is plausible, the evaluative terms used to describe them 
appear justifiable only after the presentation of the Transitivity analysis. This analysis, however, does not make an explicit argument for presenting these three types of roles in evaluative terms. The reader has to assume that the use of passive voice or the transitivity role of Carrier in a relational process could be seen as marking evicted as victims, just as the use of material processes with negative Judgement (e.g., "crush," "sweep away") can be considered a feature that construes financial, political and legal bodies as villains. And finally, it is the verbal processes that are also marked for positive or negative Judgment (e.g., "accuse," "denounce," "promise") and the role of Actor in material processes that seem to encode heroes. The statement about the use of Affect in the victims' quotes is illustrated with fitting examples but could benefit from a more detailed or technical discussion of the affective meanings. The article ends with an insightful comparison of this type of news presentation to traditional storytelling, as both genres utilize the archetypical participant roles discussed in the study.

Finally, the last chapter by Carmen Sancho Guinda is devoted to the analysis of emotional meanings in a novel visual genre, that of academic graphical abstracts (GA) submitted to high-impact scientific journals (like Cell). The author starts by pointing out how the genre of GA illustrates various disparities that tend to characterize contemporary academic discourse in general, like the tension between the need to present information objectively and at the same time promotionally, or the need to appeal to an expert audience and at the same time to other communities of practice. She then argues that GA, due to their visual nature, unpredictability of formats and imprecise guidelines for authors, cannot fulfil the functions that traditional abstracts play in academic discourse and thus can only serve as abridged and transducted (i.e., translated from one mode of communication to another) versions of the latter. Transduction into the visual mode, however, opens new opportunities for meaningmaking in which emotion and subjectivity play a major role, enhancing the scientific information but also distracting from it. The author shows how stylizations in GA merge Appreciation and Affect from the Appraisal model (Martin \& White, 2005) and lead to trivialization of scientific information. Furthermore, she gives stimulating examples of the ways trivialization manifests itself through prettification (for example, presenting chemical symbols as cartoon characters) or the use of visual/multimodal metaphor (like encoding doubt about a chemical substance through the figure of Shakespeare's Hamlet), two strategies that sometimes make GA look like instances of a different genre (for example, advertisement). Despite much critique of the genre, the author's ultimate conclusion is that GA might be a good tool for democratizing science.

The edited volume ends here and could have benefited from a concluding chapter that would tie all the interesting studies and their findings together and chart the answers to the overarching questions formulated in the introductory chapter. Despite this criticism, all in all, the book promotes a multi-faceted, interdisciplinary, and cross-cultural understanding of the complex issue of emotion in discourse. It addresses the role and expression of emotion in different languages 
and across a wide variety of contexts, presents the reader with a balanced mix of theoretical and empirical discussions, and gives voice to researchers from various theoretical paradigms and countries, even if unsurprisingly preference is given to the functional approaches. Without doubt, Emotion in Discourse is a timely and significant contribution to the field and will inspire further research on our capacity to experience affect and make sense of it through language, as well as practical applications in such areas as intercultural communication, communication at work, and L2 pedagogy, assessment or writing instruction.

(C) Marianna Ryshina-Pankova, 2020 @creative

This work is licensed under a Creative Commons Attribution 4.0 International License https://creativecommons.org/licenses/by/4.0/

\section{REFERENCES}

Alba-Juez, Laura \& Tatiana Larina. 2018. Language and emotion: Discourse-pragmatic perspectives. Russian Journal of Linguistics 22 (1). 9-37. doi 10.22363/2312-9182-2018-22$1-9-37$

Bednarek, Monika. 2008. Emotion talk across corpora. Basingstoke/New York: Palgrave Macmillan.

Brown, Penelope \& Stephen C. Levinson. (1978[1987]). Politeness: Some universals in language usage. Cambridge: Cambridge University Press.

Council of Europe. 2001. Common European framework of reference for languages: learning, teaching, assessment. Cambridge: Cambridge University Press.

Hengeveld, Kees \& J. Lachlan Mackenzie. 2008. Functional Discourse Grammar: A typologically-based theory of language structure. Oxford: Oxford University Press.

Kövecses, Zoltán. 2000. Metaphor and emotion: Language, culture, and body in human feeling. Cambridge: Cambridge University Press.

Lakoff, George \& Mark Johnson. 1980. Metaphors we live by. Chicago/London: University of Chicago Press.

Martin, James R. \& Peter White. 2005. The language of evaluation: Appraisal in English. Basingstoke/New York: Palgrave Macmillan.

Mikolajczak, Moïra. 2009. Going beyond the ability-trait debate: A three level model of emotional intelligence. E-Journal of Applied Psychology 5. 25-31.

Schwarz-Friesel, Monika. 2010. Expressive Bedeutung und E-Implikaturen--Zur Relevanz konzeptueller Bewertungen bei indirekten Sprechakten: Das Streichbarkeitskriterium und seine kognitive Realität. In W. Rudnitzky (ed.), Kultura Kak Tekst, 12-27. Moscow: SGT.

\section{Bionote:}

MARIANNA RYSHINA-PANKOVA is an Associate Professor at the German Department at Georgetown University. She has published on the application of systemic functional theory in language pedagogy and content- and language-integrated curriculum design, advanced language learner development, and foreign language assessment. 
Contact information:

Georgetown University, German Department, Washington, DC, 20057

e-mail: ryshinam@georgetown.edu

Сведения об авторе:

МАРИАННА РЫШИНА-ПАНКОВА - профессор факультета немецкого языка в Джорджтаунском университете, Вашингтон, США. Автор статей о применении системно-функциональной теории в обучении иностранному языку, а также о развитии языковых умений на продвинутом этапе обучения и оценке знаний иностранного языка.

Контактная информация:

Georgetown University, German Department, Washington, DC, 20057

e-mail: ryshinam@georgetown.edu 